\title{
La gratuidad del cargo de patrono en el régimen fiscal privilegiado. Análisis crítico y propuesta de reforma
}

\section{Esteban Palacios Ronda}

RESUMEN: Asociaciones y Fundaciones, entidades sin ánimo de lucro integrantes del denominado Tercer Sector, permiten atender necesidades reales tanto de personas desfavorecidas como de sectores y actividades caracterizadas por la persecución del interés general. Sin embargo, no puede afirmarse que los poderes públicos faciliten a estas entidades, con la decisión necesaria, la obtención de recursos con los que atender sus fines. De la misma manera que una Asociación declarada de utilidad pública puede ver revocada su calificación si obtiene recursos mediante el ejercicio de actividades económicas, una Fundación que retribuya a sus Patronos por el ejercicio de sus funciones perderá la posibilidad de acogerse al régimen fiscal privilegiado establecido por la Ley 49/2002, a resultas de la literalidad de una normativa que parece desconocer la realidad fundacional.

En la primera parte de este trabajo examinaremos la configuración gratuita del cargo de Patrono de Fundaciones, compararemos la rigidez con que el ordenamiento se produce frente a ella con los intentos de, por una u otra vía, suavizar los restantes requisitos exigidos legalmente para la aplicación del régimen fiscal privilegiado. A continuación señalaremos las consecuencias que de la gratuidad del cargo de Patrono se derivan para el buen desarrollo de la entidad y, por último, apuntaremos algunas reflexiones que entendemos permitirían subsanar lo que, a nuestro juicio, supone una rémora para el correcto funcionamiento de las Fundaciones y por ende del Tercer Sector.

PALABRAS CLAVE: Tercer Sector, Fundaciones, Mecenazgo, Tributación, Administración.

CLAVES ECONLIT: L31, L51, K34.

Cómo citar este artículo/How to cite this article: PALACIOS, E. (2021): "La gratuidad del cargo de patrono en el régimen fiscal privilegiado. Análisis crítico y propuesta de reforma”, CIRIEC-España, Revista de Economía Pública, Social y Cooperativa, 102, 329-356. DOI: 10.7203/CIRIEC-E.102.16560.

Correspondencia: Esteban Palacios Ronda, Facultad de Economía de Valencia, Departamento de Economía Aplicada, Esteban.Palacios@uv.es, ORCID: 0000-0002-9293-6329. 


\section{Expanded abstract}

\section{Unpaid nature of the position of trustee in a preferential tax regime. Critical analysis and reform proposal}

\section{Objectives}

The possibility of foundations opting to apply for a preferential tax regime provided by Law $49 / 2002$, of December 23, depends on whether these entities meet the requirements established in Art. 3 of this law. Among these requirements, the most important one in our opinion is the condition that trustees carry out their roles without remuneration. This paper examines the voluntary nature of the position of trustee and the operational issues that arise from this for the foundation, and reflects on ways of managing this situation.

\section{Methodology}

We refer to the legal requirement of the unpaid nature of the position of trustee both in the substantive and fiscal fields and we venture to suggest the inconsistency of this obligation. We study the varying degrees of rigour which are applied when assessing the unpaid nature of the position of trustee and the other conditions required for the application of the preferential tax regime as well as the consequences of this legislative option, drawing conclusions which may indicate appropriate reforms to this law.

\section{Approach}

The Third Sector, of which foundations form a part, looks to meet the needs of people and of processes worthy of special protection. This is upheld in the words of the Constitutional Court (STC 18/1984, of February 7), which declare that a characteristic of the social and legal state is that general interests are defined through an interaction between the state and social agents, where foundations play a role of crucial importance.

In our system, the non remuneration of trustees is absolute. Their remuneration implies the impossibility that the foundation can choose the preferential tax regime established by Law 49/2002. The basis for this requirement stems from purely historical reasons and from the need to prevent trustees receiving indirect financial benefit from their involvement in the foundation. However, the unpaid position of trustee is not part of the so-called "essential content" of the right to create foundations; it is simply a legislative option for the foundation. 


\section{Results}

If we compare the required unpaid position of trustee with the rest of the requirements that Law 49/2002 demands for the application of the preferential tax regime we see that its practical translation is quite different. If gratuity is absolute, the remaining requirements of Art. 3 of the LRF-ENL (with the sole exception of the destination of their assets in the event of dissolution) are softened doctrinally, jurisprudentially and legally.

Essentially, due to either the forced evolution in jurisprudence (pursuit of the general interest indirectly in Article 3.1), or to the limitations expressly established by the legal text itself (obligatory destination of at least 70\% of certain income or revenue of Article 3.2; a limit of $40 \%$ to be dedicated to economic activity other than its statutory objective or purpose of article 3.3; impossibility that certain people are main recipients or might benefit from special conditions in the use of their services of Art. 3.4), or due to different doctrinal considerations (retroactive application of the preferential regime to the foundation in formation in the case of Art. 3.7; relative tolerance in the preparation of accounts and preparation of an annual report of numbers 8, 9 and 10 of Article 3); and with the sole exception of the obligatory destination of the patrimony in case of dissolution of Art. 3.6 (really a prolongation of the need to allocate any income and revenue for purposes of general interest), there is no doubt that the requirements demanded for the application of the preferential tax regime operate, in practice, with a lower rigour than that stipulated in Law 49/2002, which, we insist, contrasts significantly with the robustness that the legislation called for when considering the trustee's position of non remuneration.

\section{Implications}

The unquestionable altruistic convictions of trustees, including the social recognition that comes with their appointment, may be sufficient reward for those who accept the position. However, with this recognition comes responsibility, a solidarity with the rest of the trustees, including even any moral damage that may be caused to the foundation by a trustee, a responsibility that many trustees overlook. Trustees are clearly accountable in the event that the foundation is immersed in a bankruptcy or tax procedure, or fails to meet its duty to ensure compliance with the legal responsibilities of data protection, or criminal compliance, or its obligation to ensure that the foundation is not used for money laundering or to channel funds or resources to persons or entities linked to terrorist groups or organizations.

\section{Practical conclusions and original significance}

The name "Trustee" encompasses two very different realities: on the one hand, purely honorary trustees who, detached from the daily life of the foundation, limit themselves to lending their good name to an altruistic cause with no liability and, on the other hand, the trustees who are involved in the day-to-day management of the foundation. We understand, however, that the trustee we call "honorary" cannot be subjected to a liability regime such as the one that exists, and, yet, with respect to the "manager" trustee, foundations need financial stability, 
not related to the initial endowment, which requires progressive streamlining of its operating capacities, bringing its responsibility more in line with commercial matters while, at the same time, allowing remuneration for services provided.

Recognizing the difficulties of the task, it would seem that the solution must be inspired by STC 18/1984, cited above, according to which "one of the characteristics of the social and legal state is that general interests are defined through interaction between the State and the social agents... that transcends the field of organization, where foundations play a role of crucial importance". For this, we insist, it is necessary to overcome the wary statist view that currently limits the undertaking of industrial or mercantile activities by foundations. That is, it is necessary to allow without prejudice the execution of economic activities by foundations, establishing the necessary controls and repositioning the trustee in a more appropriate role as a true manager of economic operators in the market.

In short, the problem of non remuneration of the trustee must be framed within a global rethinking of the tax regime of non-profit entities and of patronage in light of a constantly changing environment. This rethinking has as a premise the change of attitude of the public authorities who, overcoming their mistrust and paternalism, must establish open collaboration with civil society, especially with foundations that are not, as described by the dictionary mere "fruits of human vanity" but, in the words of Óscar Alzaga "one of the great bridges that must be built to safeguard the abyss between individuals and the State". With our paper we have tried to broaden the doctrinal debate by providing a redefinition of the figure of trustee on whom, ultimately, rests the future of a foundation.

\section{Keywords: Third Sector, Foundations, Patronage, Taxation, Administration.}




\section{Introducción}

De entre los distintos actores que conforman el Tercer Sector destacan por méritos propios las Fundaciones, "organizaciones constituidas sin fin de lucro que, por voluntad de sus creadores, tienen afectado de modo duradero su patrimonio a la realización de fines de interés general" (art. 1.2 Ley 50/2002, de 26 de diciembre, de Fundaciones -en lo sucesivo LF-). A pesar de que la noción de utilidad pública, verdadero fundamento de la materia, se encuentra ínsita en el concepto de Fundación, a estas entidades no les resulta automáticamente aplicable el régimen fiscal privilegiado previsto en la Ley 49/2002, de 23 de diciembre, de Régimen Fiscal de las Entidades sin Fines Lucrativos y de los Incentivos Fiscales al Mecenazgo (en adelante, LRF-ENL) sino que, para que puedan optar por dicho régimen, precisan cumplir de manera imperativa la totalidad de los requisitos establecidos en el art. 3 Ley 49/2002. Entre estos requisitos destaca, por lo que ahora interesa, la gratuidad en el ejercicio del cargo de Patrono.

Sentado lo anterior, bastará un breve examen a la traducción práctica de las distintas exigencias establecidas por la LRF-ENL para acceder al régimen fiscal privilegiado para concluir que la norma (interpretada por la AEAT), se produce con un rigor distintamente superior al considerar la gratuidad del cargo de Patrono que al aplicar los restantes apartados este texto legal. Tanto es así que, entendemos, no nos encontramos ante una mera opción legislativa, ni siquiera de una desacertada praxis tributaria, sino ante la exteriorización de un fenómeno más profundo e indudablemente más preocupante: la inveterada desconfianza con la que se producen los poderes públicos frente a la actuación de la sociedad civil. Esta desconfianza dificulta, a nuestro entender, la existencia de administradores profesionales y limita la actividad del Patrono al mero control de las actividades desempeñadas, lastrando de esta manera el fortalecimiento del fenómeno fundacional en el ámbito del Tercer Sector.

Para justificar nuestra afirmación examinaremos en primer lugar los elementos que configuran la noción de gratuidad en el ejercicio del cargo de Patrono y los compararemos con la implementación del resto de los requisitos exigidos por el art. 3 de la Ley 49/2002 para la aplicación del régimen tributario especial. A continuación consideraremos los problemas que de ello se derivan para la actuación de las Fundaciones y plantearemos algunas reflexiones que permitirán reenfocar este, a nuestro juicio, desafortunado rigor. 


\section{La gratuidad del cargo de Patrono en la Ley 49/2002, de 23 de diciembre, de Régimen Fiscal de las Entidades sin Fines Lucrativos y de los Incentivos Fiscales al Mecenazgo}

\subsection{Gratuidad del cargo de Patrono: imperativo normativo, reconocimiento jurisprudencial y posicionamiento doctrinal}

Como decimos, las Fundaciones, entidades sin fines lucrativos del art. 2 de la Ley 49/2002, pueden acogerse al régimen fiscal especial previsto en el Título II de esta norma, mediante la presentación de la correspondiente declaración censal (modelo 036). El incumplimiento de esta obligación conllevará, a juicio de la administración (Res. 1975/2013 TEAC, de 5 de febrero de 2015) la expulsión del régimen especial. Sin embargo lo cierto es que, tratándose de un requisito formal, de mera acreditación del requisito de fondo, debe admitirse que "pueda acreditarse de otro modo" pues "la exigencia de ese cumplimiento debe ser modulada cuando se acredite que la finalidad que perseguía el legislador (esto es, que las rentas obtenidas se destinen a fines y actividades de interés general) ha sido satisfecha" (Sentencia TSJ de Madrid 255/2017, de 12 de mayo).

Partiendo de lo anterior, tanto la Ley 50/2002 -sustantiva- como la Ley 49/2002 -fiscal- exigen preceptivamente que el cargo de Patrono sea gratuito ${ }^{1}$; extendiéndose dicha obligación de gratuidad a los administradores que representen a la entidad en las sociedades mercantiles en que participe, salvo que las retribuciones percibidas por la condición de administrador se reintegren a la entidad representada. En este caso, la retribución percibida por el administrador estará exenta en el IRPF y no existirá obligación de practicar retención a cuenta; correspondiendo entonces al pagador, a efectos de la exclusión de la obligación de retener, acreditar que las retribuciones de los administradores han sido percibidas por la entidad sin fines lucrativos a la que éstos represente (art. 5 RD 1270/2003, de 10 de octubre, por el que se aprueba el

\footnotetext{
1. La exigencia de gratuidad es reiterada por las distintas legislaciones autonómicas. Así: Madrid.- art. 12.6 de la Ley 1/1998, de 2 de marzo; Canarias.- art. 19.2 Ley 2/1998, de 6 de abril; Valencia.- art. 13.5 Ley 8/1998, de 9 de diciembre; La Rioja.- art. 16.1 Ley 1/2007 de 12 de febrero; Cataluña.- art. 332-10 de la Ley 4/2008, de 24 de abril; Andalucía.- art. 19 de la Ley 10/2005 de 31 de mayo; Castilla y León.- art. 13.4 de la Ley 13/2002 de 15 de julio; Navarra.- art 13 de la Ley Foral 10/1996 de 2 Julio; País Vasco.- art. 17 Ley 9/2016, de 2 de junio; Galicia.- art. 23 Ley 12/2006 de 1 de diciembre.
} 
Reglamento para la aplicación del régimen fiscal de las entidades sin fines lucrativos y de los incentivos fiscales al mecenazgo).

Esta noción descansa tanto en una concepción puramente honorífica del cargo de Patrono, altruista y sin ánimo de lucro, "en aras de evitar una colisión de intereses" (Serrano Chamorro, 2019: 113) como en razones históricas de reacción frente a la tradicional décima de administración percibida por los Patronos, que podía producir una "verdadera y particular vinculación de bienes a favor de los Patronos"; encontrándose "conectada, de modo muy directo, con la suspicacia que el legislador ha sentido siempre hacia la figura misma de la Fundación" (Márquez, 2007: 348).

Ahora bien, los condicionamientos históricos no siempre configuran la realidad de las instituciones. Piñar Mañas (1996: 166), examinando el denominado contenido esencial del derecho a crear fundaciones (esto es: aquella parte del contenido de un derecho sin la cual éste pierde su reconocibilidad, STC 11/1981, de 8 de abril) que debe ser respetado necesariamente por el legislador, observa que "la garantía de contenido ... no supone en absoluto la petrificación de la institución ... tampoco entran dentro del contenido esencial ciertas características que usualmente se han considerado propias de la Fundación. No es esencial que sus prestaciones sean gratuitas o lo sea el cargo de Patrono".

Sin embargo, como decimos, la gratuidad es considerada consustancial a la naturaleza del cargo; tanto es así que el Tribunal Supremo la ha calificado como legalmente inexorable, de manera que "no basta con que los patronos o representantes, desempeñen su cargo de manera gratuita ... sino que es preciso que esa gratuidad sea sustantiva, obligatoria, consustancial al régimen jurídico que lo conforma, no dependiente de las decisiones o voluntad de los órganos competentes" (STS, de 17 de marzo de 2011).

Del mismo modo, como recuerda Serrano (2019: 112), la doctrina afronta con matices la retribución del cargo de Patrono. Para López-Nieto y Mayo (2006: 183) "el cargo de patrono no debe ser retribuido en el sentido de que suponga una fuente de ingresos para el interesado suficientes o significativamente complementarios, de modo que le impriman a tal situación un cierto carácter de profesionalidad y habitualidad. Mas el cargo de patrono tampoco debe ser enteramente gratuito, pues ello produce efectos inhibitorios que desembocan a la larga en un claro perjuicio para la fundación". Para Díaz-Aguado Jalón (2018: 18) la gratuidad "encaja mal con la idea de Fundación como organización ordenada bajo criterios de eficacia económica ... si la gestión de la entidad debe ser diligente deberá encomendarse a quien pueda dedicar a ello el tiempo necesario y difícilmente puede ser así si lo hace gratuitamente".

Por excepción la exigencia de gratuidad de los miembros del órgano de gobierno no se aplica a las Asociaciones declaradas de utilidad pública (Ley Orgánica 1/2002, de 22 de marzo, reguladora del Derecho de Asociación -art. 32.1.c-), ni tampoco a las Federaciones Deportivas ni al Comité Olímpico o Paralímpico Español así como a la Cruz Roja Española y a la ONCE. En estos dos últimos supuestos únicamente han de cumplir el requisito de la gratuidad del cargo de administrador en las sociedades mercantiles en que participen dichas entidades, salvo que las retribuciones así percibidas se reintegren a la entidad que representen. De esta manera se produce la paradoja, probablemente reveladora, de que los directivos de una federación terri- 
torial de boxeo pueden ser retribuidos por sus gestiones, mientras que los Patronos de una Fundación, aunque ejerza actividades económicas con los que mantener un comedor social, no pueden serlo.

Sentado, pues, que tanto la ley fiscal (49/2002) como la ley sustantiva de fundaciones (50/2002) imposibilitan la retribución de los Patronos, el legislador pretende, con mayor o menor acierto, conseguir su indemnidad en el ejercicio del cargo. De esta manera la LF permite a los Patronos el reembolso de los "gastos debidamente justificados que el cargo les ocasione en el ejercicio de su función" y también, salvo que el fundador hubiese dispuesto lo contrario, la "retribución adecuada" fijada por el Patronato de los "servicios distintos de los de los que implica el desempeño de las funciones que les corresponden como miembros del Patronato, previa autorización del Protectorado" (art. 15.4 LF).

La posibilidad "hasta ahora inédita en la ley" de remunerar servicios prestados a la fundación distintos de los que implica el desempeño de funciones propias del patronato obedece a una "problemática reiteradamente planteada por el sector" (Exposición de Motivos Ley 50/2002) que, en palabras del Consejo de Estado (Dictamen 1636/2002, de 9 de julio), obliga a "denegar la autorización cuando se pretenda utilizar la autocontratación de manera fraudulenta o con un desvío de fondos de la fundación hacia el lucro personal de los patronos ... ya que el principio de gratuidad se enuncia de un modo categórico, como regla general, y la posibilidad de excepción aparece vinculada tanto a la voluntad del fundador como a la autorización del protectorado".

Por ello, el Protectorado rechazará la preceptiva (art. 28 Ley 50/2002) concesión de la autorización cuando el servicio encubra una remuneración por el ejercicio del cargo o cuando el valor de la contraprestación que deba recibir la fundación no resulte equilibrado (art. 34.3 RD 1337/2005, de 11 de noviembre, por el que se aprueba el Reglamento de fundaciones de competencia estatal; en lo sucesivo RF). Y también, ante la posibilidad de encubrir una vía indirecta de retribución del Patrono, el Patronato precisa autorización del protectorado para designar como Patrono a una persona, natural o jurídica, que mantenga un contrato en vigor con la fundación (34.4 RF), o cuando el contrato se celebre con una persona física que actúe como representante del Patrono (art. 28 Ley 50/2002). Como vemos el ordenamiento prohíbe el ánimo de lucro obligando al Patrono a ejercer su cargo gratuitamente y a recabar autorización del Protectorado para que el Patronato pueda retribuir a los Patronos por los servicios distintos de los inherentes al cargo (art. 15.4 Ley 50/2002). Pero el art. 27 LF establece también "en la misma línea una vinculación ingresos-fines, de manera que se eviten las desviaciones que al final puedan aproximarse a un lucro indirecto" (Calvo Ortega, 2016: 1046).

Entendemos que esta configuración resulta especialmente desacertada. Indudablemente es necesario algún tipo de control por parte del Protectorado que impida "la arbitrariedad en su constitución y funcionamiento" (Orejas, 2019: 318) la desnaturalización del funcionamiento de la Fundación. Pero el sistema elegido no parece realista. Pensemos en alguna gestión o servicio urgente que deba ser atendido imperativamente por los Patronos. Según el art. 34 RF, para conseguir la preceptiva autorización del Protectorado sería necesario: convocar debidamente al Patronato (y aquel que esté en contacto con la realidad de las Fundaciones conocerá 
las dificultades que en ocasiones esto puede suponer), obtener la mayoría de votos necesaria, que por el Secretario se certifique el acuerdo y su coste máximo (lo cual puede haber requerido previamente la elaboración de un proyecto redactado por un profesional), formular una memoria explicativa de las circunstancias concurrentes y de las ventajas que se derivan para la Fundación, presentar esta documentación ante la administración y esperar la correspondiente resolución del expediente, bien expresa bien por silencio administrativo positivo en el plazo de tres meses.

Se trata pues de un sistema tan alejado de la realidad que no cabe imaginar siquiera que el legislador haya querido facilitar la actuación de los Patronos. De haberlo así pretendido, se hubiese establecido un control a posteriori de las actuaciones del Patrono, con posibilidad de reclamación contra éste por parte de la administración, de la propia Fundación y también por los terceros perjudicados, que no coartara sus posibilidades de actuación y que no revelara, como es el caso, la inmerecida desconfianza que los poderes públicos sienten hacia el Tercer Sector.

\subsection{Reembolso de los gastos ocasionados en el desempeño de sus funciones}

El segundo elemento que modaliza la necesaria gratuidad del cargo consiste en el derecho del Patrono al reembolso de los gastos (anticipo, reembolso e indemnización de daños, dice el art. 322-10 de la Ley 4/2008, de 24 de abril, del Libro Tercero del Código Civil de Cataluña), debidamente justificados, ocasionados por el desempeño de su función, con los límites establecidos en sede del IRPF para ser considerados dietas exceptuadas de gravamen (art. 9 RIRPF).

Dado que el art. 3.5 o de la Ley 49/2002 no recoge la posibilidad de que el fundador en el acto de constitución establezca lo contrario, a diferencia de lo ocurría con el art. 13.6 de la anterior Ley 30/1994, la doctrina suele entender que la disposición contraria "de los estatutos o la manifestación de voluntad del fundador deberá entenderse por no puesta" (Marimón y Olavarría, 2008: 409). Probablemente esta solución resulte conforme al art. 11.2 de la Ley $50 / 2002$, pero no parece entendible la decisión del legislador de limitar la voluntad del fundador en un punto que, de admitirse, no haría sino reforzar la gratuidad del cargo. De hecho algunas Comunidades Autónomas sí que admiten la posibilidad de que el fundador prohíba a los Patronos el reembolso de los gastos ocasionados. Así ocurre con las fundaciones canarias (art. 19 Ley 2/1998, de 6 de abril), de La Rioja (art. 16.1 Ley 1/2007, de 12 de febrero), andaluzas (art. 19 Ley 10/2005, de 31 de mayo) y de Castilla y León (art. 13 Ley 13/2002 de 15 de julio, la cual permite a la Junta de Castilla y León establecer el porcentaje máximo de las rentas e ingresos de las Fundaciones que pueden destinarse a sufragar los gastos del Patronato).

Se trata de un reembolso al Patrono en el que su carácter compensatorio prima sobre el remuneratorio que, en principio, busca evitar el enriquecimiento injusto de la fundación pero que transluce una evidente manifestación de desconfianza hacia la realidad fundacional. Veamos el por qué de esta afirmación. 
En primer lugar, por lo que respecta a la exención de las dietas percibidas por los patronos por los desplazamientos y de los gastos ocasionados como consecuencia de las reuniones a las que asisten, la DGT considera (V1110/2017, de 10 de mayo) que quedan únicamente exonerados de gravamen las asignaciones para gastos de locomoción y para gastos de manutención y estancia cuando son percibidas por el trabajador por cuenta ajena que, en virtud del poder de organización que asiste al empresario, debe desplazarse fuera de su centro de trabajo para desarrollar el mismo. Lo así establecido únicamente es de aplicación a los contribuyentes que perciben rendimientos del trabajo como consecuencia de una relación laboral (estatutaria en el caso de los funcionarios públicos) en la que se dan las notas de dependencia y alteridad. En consecuencia, a las cantidades percibidas para compensar los gastos de desplazamiento y estancia en que puedan incurrir los patronos de la fundación, dado que no existe una relación laboral, no les resultan aplicables lo dispuesto en los arts. 17.1.d) LIRPF y 9.2.b) de su Reglamento.

No obstante, señala la DGT en la resolución citada, cabría la posibilidad de apreciar la existencia de un «gasto por cuenta de un tercero» Así, no existirá retribución si: "la fundación pone a disposición de los representantes los medios para que estos acudan al lugar en el que deben ejercer sus funciones, es decir, proporciona el medio de transporte y, en su caso, el alojamiento" o bien cuando "la fundación reembolsa a los representantes los gastos en los que han incurrido para desplazarse hasta el lugar donde van a prestar sus servicios y estos acreditan (de forma justificada) que estrictamente vienen a compensar dichos gastos pues no existe ningún beneficio particular para ellos". Las cantidades percibidas por este concepto no podrán exceder de los límites previstos en la normativa del IRPF para ser consideradas dietas exceptuadas de gravamen.

En caso contrario, estaremos en presencia de una verdadera retribución (contraviniéndose lo establecido en el art. 3.5ำ Ley 49/2002), en cuyo caso, las cuantías percibidas estarían plenamente sometidas al Impuesto quedando sujetos a retención los importes satisfechos si la fundación reembolsa a los representantes los gastos en los que han incurrido para desplazarse hasta el lugar donde van a prestar sus servicios y estos no acreditan que estrictamente vienen a compensar dichos gastos o bien abona a los patronos una cantidad para que estos decidan libremente cómo asignarla.

En segundo lugar, porque el derecho al reembolso de los gastos en que haya incurrido el Patrono no se corresponde con los realmente efectuados sino que, antes incluso de que pueda evidenciarse su necesidad, está sometido a límites. Así (art. 33 RF) la suma de los gastos de la administración de la fundación y los gastos de los que los patronos tienen derecho a ser resarcidos no puede superar la cifra mayor del $5 \%$ de los fondos propios o del $20 \%$ del resultado contable corregido con los ajustes previstos en el art. $32 \mathrm{RF}$. Incluso, en su ámbito de sus competencias, la Junta de Castilla y León puede fijar un porcentaje máximo de los ingresos fundacionales que pueden destinarse a sufragar los gastos del patronato (art. 13 Ley 13/2002, de 15 de julio).

Ya al tiempo de la promulgación de la Ley 49/2002 observaba Pedreira (2003:112) que "se debería haber tenido en cuenta que, muchas veces, no se está retribuyendo solamente los gas- 
tos de desplazamientos a las asambleas. Por lo general, estos órganos están formados por personas con importantes ocupaciones socio-laborales y cuya asistencia a este tipo de reuniones les pueden acarrear unos costes mucho más elevados que los establecidos (en el IRPF) de ahí que no compartamos se haya establecido un límite de retribución tan estricto, pues ello puede dar lugar a que muchos patronos, sobre todo en grandes entidades, renuncien a sus cargos con el problema de gestión que esto puede conllevar para el tercer sector".

Con todo, es difícil entender estas limitaciones al derecho de reembolso que vincula las cantidades a reembolsar a los Patronos a unos límites establecidos en otra norma (LIRPF), para otros destinatarios (trabajadores por cuenta ajena) y para otros fines (dietas exceptuadas de gravamen). En definitiva, el legislador no articula un sistema de control a posteriori por parte del Protectorado, que debiera ser adaptable a la multiplicidad de situaciones posibles, sino que, conscientemente, limita la indemnidad de un Patrono que asume una serie de gastos presumiblemente beneficiosos para la Fundación. Por ello no cabe sino colegir que el legislador, limitando las posibilidades de actuación de los Patronos, entorpece la actividad de las fundaciones, tomando para sí el control de actividades altruistas propias de la sociedad civil.

La gratuidad del cargo de Patrono es igualmente de aplicación a los administradores que representen a la Fundación en las sociedades mercantiles en que participe, salvo que las retribuciones percibidas por su condición de administrador se reintegren a la entidad que representen. La cuestión se planteó en la Consulta V0258/2016, de 25 de enero, relativa a una persona física, vocal (retribuido) en el Consejo de Administración de una SRL unipersonal. El propietario de esta SRL es, a su vez, fundador principal de una Fundación en la que la misma persona vocal del Consejo de administración de la SRL ostenta el cargo de Patrono. Fallecido el propietario único de la sociedad, sus participaciones pasan testamentariamente a ser propiedad de la Fundación, produciéndose de esta manera la reunión en una misma persona de los cargos de Patrono de la Fundación y administrador de la SRL.

En esta resolución la DGT se limita a transcribir el art 3.5 para concluir que el precepto "es claro a este respecto exigiendo la gratuidad de los cargos (de gobierno), aplicándose igualmente a los administradores que representen a la entidad en las sociedades mercantiles en las que participe (salvo que) las retribuciones percibidas se reintegren a la entidad que representen. En caso contrario, se entenderá incumplido el requisito del art. 3.5으, no pudiendo la entidad acogerse al régimen fiscal especial". Posteriormente se reitera esta idea en la poco didáctica Consulta V1582/2018, de 7 de junio de 2018, (ampliación de la Consulta V0258-2016), a tenor de la cual "no se puede entender que el precepto se refiera a la representación legal de la fundación ... una interpretación teleológica del espíritu normativo debe llevarnos a concluir que la representación a la que se refiere el artículo 3.5--4 de la LRF-ENL ha de entenderse en términos de representatividad (en cuanto a que el administrador de la mercantil actúe o ejerza su cargo velando por los intereses de la Fundación, pudiendo incluso haber sido nombrado por ella) y no de representación legal (que efectivamente, corresponde al administrador legal para las entidades mercantiles o al Patronato, en caso de las fundaciones). Otra interpretación diferente vaciaría el artículo de contenido, toda vez que a la "entidad", entendida ésta como la Fundación, no la representará legalmente nunca un administrador sino en todo caso un 
miembro del Patronato". Y concluye: "debe entenderse, por tanto, que se cumple el requisito de ser administrador representante (en términos de representatividad, no necesariamente de representación legal) de la Fundación en la entidad participada".

Como vemos, la posición de la Administración oscila desde una lacónica motivación inicial (CV0258/2016) hasta la oscuridad de la Consulta V1582/2018. Sin embargo, la norma parece olvidar que el nombramiento de los miembros del Consejo no corresponde necesariamente a la entidad que posee una determinada participación en el capital social, sino a la Junta General de la sociedad participada. Si la elección de consejero recae en la propia Fundación, ésta debe designar una persona física que la represente y entonces las retribuciones a percibir por el administrador no corresponden al representante sino a la propia Fundación porque "estos administradores actúan en nombre y por cuenta de la titular de las acciones, la entidad sin fines lucrativos, por lo que las retribuciones percibidas no son un ingreso del administrador sino de la propia entidad sin ánimo de lucro. En este caso la obtención de la renta ... corresponde a la fundación y no a la entidad que la representa como accionista de otra y que está obligado a reembolsar las cantidades que percibe"(consulta V0249/2009, de 11 de febrero; véase también consulta V2015/2017, de 26 de julio).

En definitiva, como ya señaló Pedreira (2003: 114), "nos encontramos ante un precepto que desconoce por completo la realidad económica de nuestro país, y muy especialmente las referencias existentes entre el sector empresarial y el no lucrativo. ¿Cómo se le puede pedir a una entidad sin fines lucrativos que nombre a un miembro de un Consejo de Administración de un Banco o de una compañía eléctrica y que ese gestor de la sociedad no perciba remuneración alguna? ¿Qué gestores puede encontrar la entidad con esas condiciones retributivas? Realmente esta situación no va sólo en contra de las entidades sin fines lucrativos, sino que perjudica igualmente a las sociedades participadas por ellas. Consideramos que este requisito carece de justificación, salvo el tradicional temor a considerar que las entidades no lucrativas puedan convertirse en cabecera de un holding".

Especial trascendencia práctica plantea el supuesto en el que la Fundación contrate un seguro que cubra la responsabilidad civil en que puedan incurrir sus Patronos en el ejercicio de las funciones inherentes a su cargo. En principio (Consulta V2417/2008, de 16 de diciembre), si el contrato de seguro cubre la responsabilidad civil de una persona que ostenta la condición de trabajador en los términos del art. 42.2.e/ LIRPF (persona que presta servicios retribuidos por cuenta ajena y dentro del ámbito de organización y dirección de otra persona, física y jurídica, denominado empleador o empresario), las primas o cuotas satisfechas por la empresa no tendrán la consideración de rendimientos del trabajo en especie. Por el contrario, la prima que cubra la responsabilidad civil del Patrono, en su condición de tal, sin que medie una relación laboral con la Fundación, tendrá la naturaleza de retribución en especie sobre la que existirá la obligación de practicar ingreso a cuenta quebrándose con ello el requisito de gratuidad exigido.

La Consulta V0869/2017, de 10 de abril, se refiere a una póliza de seguro, en la que la definición del colectivo asegurado es "amplia e innominada", siendo las personas aseguradas los "administradores, directivos o patronos así como cualquier persona física, cualquiera que sea 
la denominación de su cargo, que tenga atribuidas facultades de más alta dirección de la sociedad, también se extiende al cónyuge o pareja de hecho, la masa hereditaria, herederos, representantes legales o albaceas de la persona asegurada". Pues bien, en este caso la AEAT, a la vista del art. 42 de la LIRPF concluyó, sorprendentemente sin mayores consideraciones, que las primas satisfechas no constituyen una retribución en especie (Véase también CV 0868/2017, de 10 de abril).

\subsection{Ponderación de la gratuidad del cargo de patrono}

Llegados a este punto y de acuerdo con lo expuesto, no podemos defender una gratuidad del cargo de Patrono con carácter absoluto. Antes al contrario, si el objetivo de la norma es la protección de entidades que, como las Fundaciones, coadyuvan a la consecución de fines de interés general, no cabe establecer rémora alguna -mediante una prohibición general del carácter retribuible de su órgano de administración- a la eficiencia de estas entidades integrantes del Tercer Sector. Por el contrario la norma debiera centrar sus esfuerzos en velar por el efectivo destino de las rentas e ingresos de las fundaciones (así como el de su patrimonio en caso de su disolución) a los objetivos constitutivos de la entidad, imposibilitándose cualquier desviación respecto a los fines de interés general perseguidos. Esta es la cuestión nuclear del régimen y a la que deben supeditarse, de forma ponderada, el resto de requisitos establecidos en el art. 3 de la Ley 49/2002.

A mayor abundamiento, traigamos a colación la Sentencia 1020/2013, de 19 de noviembre, del TSJ de Madrid, en la que se resuelve la denegación por la AEAT de la aplicación del régimen fiscal especial a una Fundación residente en Suecia por no figurar inscrita en el Registro español de Fundaciones. El TSJ (en base a los pronunciamientos del Tribunal de Justicia de la Unión Europea -Sentencia de fecha 14 de septiembre de 2006; asunto C-386/04, Centro di Musicologia) tras afirmar que las competencias de los Estados miembros en materia fiscal no pueden ser utilizadas para obstaculizar las libertades consagradas en el ordenamiento comunitario, en concreto la libertad de circulación de capitales, fundamenta lo siguiente: "cuando una fundación ha sido reconocida de utilidad pública en un Estado miembro, las autoridades de otro Estado miembro no pueden negar a la fundación el derecho a la igualdad de trato basándose sólo en que no está establecida en su territorio". Tras ello el TSJ procede a verificar si la fundación residente en Suecia cumple los requisitos exigidos a las fundaciones con residencia en España para gozar de la exención tributaria. Afirma el Tribunal en la resolución anteriormente citada que "la aplicación de la exención fiscal no requiere una absoluta identidad de circunstancias entre las fundaciones españolas y las fundaciones de otro Estado miembro, sino que se encuentren en una situación objetivamente comparable".

Así el TSJ al comparar los diez requisitos establecidos en el art. 3 de la Ley 49/2002, advierte que la única discrepancia entre los ordenamientos sueco y español se manifiesta en relación el carácter remunerado del cargo de Patrono -Junta Directiva- de las fundaciones con 
residencia en Suecia y que, ello no obstante, no impide superar dicho análisis de comparabilidad que proclama el Tribunal de Justicia de la Unión Europea (haciendo así de peor condición a las fundaciones residentes en España que incumplen este requisito respecto a sus homólogas suecas). En definitiva, pues, el análisis del cumplimiento de los requisitos que han de cumplir las ENL ha de efectuarse, atendiendo a la finalidad de la norma, en términos de proporcionalidad y la retribución del órgano de gobierno no le otorga un carácter absoluto pues el carácter privilegiado del régimen fiscal especial establecido para las entidades sin fines lucrativos se traduce en que las rentas que obtengan se destinen a fines y actividades de interés general.

\section{Requisitos exigidos en el artículo 3 de la Ley 49/2002 para acceder al régimen fiscal privilegiado}

Hasta aquí hemos examinado la, como posteriormente veremos, desacertada rigidez que preside la regulación de la gratuidad del cargo de Patrono. Comparemos ahora la concreción del resto de los requisitos establecidos por la LRF-ENL para la aplicación del régimen privilegiado, adelantando la conclusión de que el rigor con que el legislador configura la gratuidad del cargo de Patrono contrasta, aun considerando las excepciones contenidas en el mismo punto quinto de este art. 3 , con los intentos efectuados, a través de distintas vías, para flexibilizar los restantes apartados del citado precepto de la Ley 49/2002.

Importa subrayar dos notas comunes a los requisitos establecidos por la Ley 49/2002 para el acceso al régimen fiscal privilegiado: se trata de exigencias de configuración legal; es decir, siempre que se respeten los principios impositivos constitucionales (art. 31.1 CE), capacidad económica, justicia, igualdad, progresividad, no confiscatoriedad, el legislador puede configurarlos con la amplitud que estime conveniente. Además, la prueba de estos requisitos es una cuestión de hecho que, en cada caso, deberá ser probada por cualquier medio de prueba admitido en de hecho ante los órganos competentes de la administración tributaria" (CV0750/2015, de 9 de marzo).

En primer lugar, el art. 3.1을 de la Ley 49/2002 exige que los fines perseguidos por la Fundación sean de interés general, entendiendo por tal aquel que "beneficia a un grupo indeterminado de ciudadanos ... sea objetivo prioritario o no de las Administraciones Públicas" (Pedreira, 2003: 89). Ante el silencio de la Ley 49/2002, se discutió si la Fundación debe perseguir estos fines de interés general de manera directa o si pudiera entenderse cumplido este requisito de forma indirecta esto es, destinando sus ingresos a otras fundaciones.

Aunque la AEAT, en una "posición extrema que ... no se sustentaba en argumento alguno" (Martín Dégano, 2015: 142) había exigido tradicionalmente la realización directa de sus actividades (CV 2344/2013), tras la SAN, de 1 de octubre 2015, se vio obligada a admitir una realización indirecta dado que "en ningún momento ni la ley sustantiva ni la fiscal exige que 
la Fundación realice de modo directo una actividad de fin general, sino que su obligación no es otra que la de perseguir fines de interés general, sin que quepan añadidos o interpretaciones que van más allá de la norma". Así, en la Consulta V2937/2019, de 23 de octubre, la DGT considera cumplido el requisito del art. 3.2ํㅡㄹ aun cuando la fundación no destinara sus fondos de forma directa a la realización de actividades de interés general, mediante el destino de los fondos a otras entidades acogidas a la Ley 49/2002, siempre que se efectúe una labor de seguimiento y control activo en los proyectos seleccionados. Vemos, pues, cómo las reticencias de la administración ante el art. 3.1ํㅡ Ley 49/2002 han sido vencidas jurisprudencialmente, lo que en definitiva ha permitido facilitar la actuación de las Fundaciones.

En segundo lugar, según el art. 3.2ํㅡ Ley 49/2002 la Fundación debe destinar a la realización de sus fines un mínimo del 70\% de las rentas e ingresos enumeradas en las letras a), b) y c) de dicho apartado, calculadas en la forma señalada por los arts. 32.5 RF y 25 de la Ley 50/2002. Obsérvese que nos encontramos ante la "esencia definitoria de las entidades sin fin lucrativo" (Eseverri, 2008: 697), que impone a sus rentas un destino alternativo a su imposible distribución (Blázquez y Martín Dégano, 2012: 57): aplicar en el plazo de cinco años (el periodo comprendido entre el inicio del ejercicio en que se hayan obtenido las respectivas rentas e ingresos y los cuatro años siguientes al cierre de dicho ejercicio) un mínimo del $70 \%$ de las rentas obtenidas a fines de interés general, destinándose el resto a incrementar la dotación patrimonial o las reservas.

Pese a la importancia conceptual de esta idea, auténtico valladar frente a las decimonónicas manos muertas, esta exigencia resulta suavizada en la práctica: la norma exige destinar no la totalidad sino solamente el 70\% de sus rentas e ingresos. Además, según la Ley 50/2002 (art. 27), en el cálculo de dicho porcentaje no se incluyen las rentas obtenidas en la transmisión onerosa de inmuebles en los que la entidad desarrolle su actividad propia de su objeto o finalidad específica, siempre que se reinvierta en inmuebles en los que concurra dicha circunstancia. Sin embargo, la ley fiscal (art. 3.2ํ․b) no limita la reinversión en inmuebles sino que amplía esta posibilidad a cualesquiera bienes y derechos afectos a su objeto finalidad específica. Es decir, la norma fiscal quiere suavizar en este punto el texto sustantivo.

En principio, el incumplimiento de cualquiera de los requisitos establecidos en el art. 3 de la Ley 49/2002 determinará para la entidad la obligación de ingresar la totalidad de las cuotas correspondientes al ejercicio en que se produzca el incumplimiento, junto con los intereses de demora que procedan (art. 14.3 LRF-ENL). Sin embargo, en el supuesto ahora analizado (art. $3.2^{\circ}$ ) la cantidad a ingresar a resultas de dicho incumplimiento será, exclusivamente, las relativas al ejercicio en que se obtuvieron los resultados e ingresos no aplicados correctamente. En palabras de Blázquez y Martín (2012: 73): "podría entenderse que el incumplimiento de este requisito debería implicar no solo la devolución de las cuotas de un ejercicio (el de la obtención de las rentas e ingresos), sino todos los demás hasta completar el plazo de cinco años, pues realmente no se ha cumplido el requisito durante los mismos. Sin embargo, la norma es clara al restringirlo únicamente a ese ejercicio. Cuando la Ley 49/2002 ha querido ampliarlo a otros ejercicios, lo ha hecho expresamente, como en el caso del requisito del artículo 3.6 (destino en caso de disolución), en el que ese mismo párrafo segundo del art. 14.3 señala que 
la devolución corresponderá a las cuotas correspondientes al ejercicio en que se produzca el incumplimiento (el de la disolución) y a los cuatro anteriores".

El tercer requisito exigido para que una entidad sin fines lucrativos pueda optar por el régimen privilegiado consiste en que "la actividad realizada -por la Fundación- no consista en el desarrollo de explotaciones económicas ajenas a su objeto o finalidad estatutaria", requisito que se entiende cumplido si "importe el neto de la cifra de negocios del ejercicio correspondiente al conjunto de las explotaciones económicas no exentas ajenas a su objeto o finalidad estatutaria no excede del $40 \%$ de los ingresos totales de la entidad ... siempre que no se vulnere las normas de defensa de la competencia en relación con empresas que realicen la misma actividad" (art. 3.3ํㅡㄴ.ENL). Es decir, la fundación puede realizar directamente actividades mercantiles siempre que el objeto de su actividad coincida con el fin fundacional (art. $24 \mathrm{LF)}$; de lo contrario solo cabrá actuar bien a través de su participación en sociedades bien en actividades complementarias o accesorias a su actividad propia.

Esta exigencia es discutida doctrinalmente. Para Rodrigo Ruiz (2017: 196), "las bonificaciones a una entidad en función del origen de sus beneficios ... transforman un impuesto directo con vocación de generalidad como el Impuesto sobre Sociedades en una simple adición de impuestos de producto que, al igual que los antiguos impuestos a cuenta, termina gravando de manera distinta e individualizada cada particular y específica fuente de renta". Para otros, la necesidad de no desvirtuar el concepto de fundación como entidad sin ánimo de lucro exigiría "ser mucho mayor el volumen de ingresos obtenidos por la vía de actividades económicas cuyo objeto esté realizado o sea accesorio a los fines ... que los ingresados por otra vía" (Meco Tébar, 2008: 709).

Para Pérez Escolar, esta modalidad de fundación-empresa, llamada dotacional "presenta en nuestro ordenamiento jurídico importantes obstáculos legislativos a su ejercicio, a nivel estatal y autonómico, cuya razón de ser parece encontrarse en la configuración del derecho de fundación al servicio de fines de interés general sin tener en cuenta que estos fines de interés general no se desvirtúan cuando se obliga a que los beneficios económicos de la empresa reviertan en la satisfacción de los mismos y no en ganancia de sujetos particulares" (Pérez Escolar, 2008: 119).

Pero, en definitiva, el legislador ha vuelto a facilitar el acceso al régimen fiscal privilegiado, excluyendo una cifra tan significativa como el $40 \%$ de los ingresos de la Fundación. Así, aunque se esté ejerciendo una actividad mercantil, "la Ley finge que no la está desarrollando ... pues aunque la actividad no es coincidente con el fin estatutario, no resulta ajena al objeto de interés general perseguido por la Fundación" (Eseverri, 2008: 702). Así pues, con independencia de la posible exención de determinadas explotaciones económicas (art. 7 Ley 49/2002), la verdadera razón de ser de la norma estriba, insistimos, en una decidida voluntad del legislador de atemperar el rigor del precepto que contrasta con el rigor con que se produce en sede de gratuidad del Patrono.

El art. 3.4ํㅡㄹ Ley 49/2002 impone también la necesidad de que los "fundadores, asociados, patronos, representantes estatutarios, miembros de los órganos de gobierno y los cónyuges o parientes hasta el cuarto grado no sean los destinatarios principales de las actividades funda- 
cionales, ni se beneficien de condiciones especiales para utilizar sus servicios". Esta exigencia no puede calificada como de "simple componente estructural" (García y Pindado, 2016: 132), sino que busca evitar la utilización de los beneficios fiscales en provecho de personas determinadas (Eseverri, 2008: 707).

Sin embargo, la norma refleja la voluntad del legislador de limitar su rigor al excepcionar de su ámbito de aplicación las actividades de investigación científica y desarrollo tecnológico, a las actividades de asistencia social o deportivas a que se refiere el artículo 20, Uno, números 8. y y 13.․ㅡ, respectivamente, de la Ley 37/1992 del IVA, a las fundaciones cuya finalidad sea la conservación y restauración de bienes del Patrimonio Histórico Español que cumplan las exigencias de la Ley 16/1985, de 25 de junio, del Patrimonio Histórico Español, o de la Ley de la respectiva Comunidad Autónoma que le sea de aplicación, en particular respecto de los deberes de visita y exposición pública de dichos bienes; excepciones a las que doctrinalmente se añade las fundaciones del sector público, a las que "una futura reforma debería excluir al igual que en el art. 3.5”” (Blázquez y Martín: 2012, 106).

El art. 3.6ํㅡ Ley 49/2002 exige que, caso de disolución, su patrimonio se destine a alguna de las entidades previstas en los arts. 16 a 25, o a entidades públicas no fundacionales que persigan fines de interés general, siempre que esta circunstancia esté contemplada en el negocio fundacional o en los estatutos de la entidad disuelta. Aunque para Martín Pascual (2003: 52) la fundación destina su patrimonio tras la extinción a entidades que merecen al legislador suficiente confianza por cumplir los requisitos legales, para Caffarena (2009: 47) esta posibilidad supone poner en peligro el prestigio de la institución. En cualquier caso, hay que reconocer que, nos encontramos ante el único supuesto en que el legislador actúa con un nivel de exigencia semejante al de la gratuidad de los patronos pues nos hallamos ante la última aplicación de las rentas e ingresos de la Fundación.

En cuanto a la necesaria inscripción registral (art. 3.7º), dado que la inscripción en el Registro de Fundaciones tiene naturaleza constitutiva (art. 4.1 LF) no deberían plantearse especiales dificultades (Peñalosa, 2012: 366). Sin inscripción, la todavía inexistente Fundación no puede acceder al régimen fiscal privilegiado y si transcurren seis meses desde el otorgamiento de escritura sin que los Patronos hayan instado su inscripción, el Protectorado (13.2 LF) debe cesar a los Patronos y proceder al nombramiento de otros nuevos, previa autorización judicial en los términos STS 782/2019, de 6 de junio, relativo a la Fundación España/Colombia.

Sin embargo doctrinalmente se busca también atenuar el rigor del precepto recordando para ello la situación planteada por la anterior Ley 30/1994 de Fundaciones y de Incentivos Fiscales a la Participación Privada en Actividades de Interés General, en la cual (art. 46.1) el reconocimiento de los beneficios fiscales a una Fundación no se producía desde la comunicación de la opción a la Administración sino que éstos se retrotraían a la fecha de su constitución cuando entre ésta y la de solicitud de inscripción en el Registro no hubiera transcurrido más de un mes. Por ello, Blázquez y Martín (2012: 126) abogan por la aplicación de los beneficios fiscales previstos en la Ley 49/2002 a la fundación en formación. En definitiva, un interpretación amplia del supuesto, que busca flexibilizar incluso el carácter constitutivo de la inscrip- 
ción y que nuevamente contrasta con el rigor con que el ordenamiento jurídico se actúa ante una posible retribución del Patrono.

El último requisito establecido por la Ley 49/2002 consiste en el cumplimiento de los deberes contables previstos en los números $8^{\circ}, 9^{\circ}$ y $10^{\circ}$ de su art. 3 , deberes que se erigen como elementos no esenciales, complementarios del régimen fiscal especial, en la medida de que con ellos se persigue un "control público que impida que bajo el amparo de la protección de intereses altruistas se alimenten intereses privados" (Martín Pascual, 2003: 55). Sentada su obligatoriedad, jurisprudencialmente las consecuencias de su incumplimiento son obvias: la pérdida de los beneficios fiscales (véase por todas STSJ Galicia, 36/2009, de 28 de enero); sin embargo la doctrina aboga por una interpretación proporcional del requisito, de manera que la expulsión de una entidad no lucrativa de la Ley 49/2002 sólo debe producirse cuando del examen de sus cuentas se desprende que la ENL no cumple fines de interés general (López Díaz, 2001: 66).

De lo apuntado se desprende que, bien por la evolución a que ha obligado la jurisprudencia (persecución del interés general de manera indirecta del art. 3.1ํ), bien por las limitaciones que expresamente establece el propio texto legal (destino obligado de al menos el $70 \%$ de determinadas rentas e ingresos del art. 3.2ㅜ; límite del $40 \%$ a la consideración de actividad económica ajena a su objeto o finalidad estatutaria del art. 3.3ㅜ; imposibilidad de que determinadas personas sean destinatarios principales o se beneficien de condiciones especiales en la utilización de sus servicios del art. 3.4ํำ), bien por distintas consideraciones doctrinales (aplicación retroactiva del régimen privilegiado a la fundación en formación en el caso del 3.7; relativa tolerancia en la formulación de cuentas y elaboración de una memoria anual de los números 8o , 9o y 10ํ del art. 3); y con la sola excepción del destino obligado del patrimonio en caso de disolución del art. 3.6 (en tanto prolongación del requisito esencial del régimen, es decir, el destino de sus rentas e ingresos a fines de interés general), resulta incontestable que los requisitos exigidos para la aplicación del régimen fiscal privilegiado operan en la práctica con un rigor inferior al que parece desprenderse de la lectura de la Ley 49/2002, lo cual, insistimos, contrasta sobremanera con la contundencia con la que se produce el ordenamiento al considerar la gratuidad del Patrono.

\section{Efectos de la gratuidad del cargo de Patrono en el correcto funcionamiento de la Fundación y propuestas de reforma}

Hasta aquí hemos considerado el innegable rigor con que el ordenamiento considera la gratuidad del cargo. Debemos plantearnos ahora las consecuencias prácticas que se derivan de esta 
opción legislativa. Tal vez las indudables convicciones altruistas de los Patronos, incluso el reconocimiento social que lleva aparejado su nombramiento, puede ser suficiente recompensa para quien acepta ostentar el cargo. Sin embargo la contrapartida a este reconocimiento se encuentra en la asunción de una responsabilidad, solidaria (237 LSC), que comprende incluso el daño moral que pueda ser causado a la Fundación (Marimón y Olavarría, 2008: 439), de contornos en ocasiones poco nítidos, de la que los Patronos no suelen ser conscientes.

Aunque solo sea a título de ejemplo traigamos a colación un caso real: un exitoso profesional del mundo de las bellas artes acepta formar parte del Patronato de una conocida Fundación. Dado el carácter puramente honorífico de su actuación no cabía plantear la posibilidad de que con su conducta se pudiere ocasionar perjuicio alguno para la entidad, por lo que la cuestión se limitó a dilucidar si el patrimonio personal del nuevo Patrono puede verse comprometido a resultas de reclamaciones efectuadas por terceros; como vemos una cuestión indudablemente transcendente a la que, en principio, se debería poder responder, de manera categórica, con un sí o con un no, pero no regulada expresamente ni en el art. 17 LF ni en las distintas legislaciones autonómicas excepción hecha del régimen propio de las fundaciones catalanas -332.11.5 CCC-). Incluso la ley gallega de 1992 dejó de hacerlo tras su reforma de 1 de diciembre de 2006.

La perplejidad del nuevo Patrono aumentó, aún más, al conocer que si la Fundación era declarada en concurso culpable (art. 172-bis Ley 22/2003, de 9 de julio, Concursal) podía quedar personalmente obligado a atender los créditos insatisfechos, pero que en este punto estaba también sujeto a discusión si nos encontraríamos ante una responsabilidad por daños (indemnizatoria, precisa probar el nexo entre la conducta del patrono y el perjuicio causado a los acreedores) o por deudas (punitiva, sin necesidad de probar conexión causal alguna), con resoluciones probablemente diferentes según el juzgado al que corresponda el conocimiento del asunto. Todo ello sin entrar en la responsabilidad del patrono por no instar el concurso de la fundación del (art. 5 LC), o en los supuestos de responsabilidad solidaria o subsidiaria previstos en la Ley General Tributaria (arts. 42 y 43 LGT Ley 58/2003, de 17 de diciembre), o su deber de velar por el cumplimiento de los deberes de protección de datos (L0 3/2018, de 5 de diciembre) o de compliance penal (art. 31 bis del Código Penal); por no hablar de su obligación de velar para que la Fundación "no sea utilizada para el blanqueo de capitales o para canalizar fondos o recursos a las personas o entidades vinculadas a grupos u organizaciones terroristas" (art. 39 Ley 10/2010 de 28 de abril, de Prevención, Blanqueo de Capitales y de la Financiación del Terrorismo).

En definitiva, tenemos un Patrono que asume una responsabilidad personal, en los términos ahora simplemente esbozados, pero que al mismo tiempo ocupa una posición muchas veces honorífica por la que conceptualmente no puede percibir retribución alguna. Todo ello unido a la imposibilidad, simplemente fáctica, de que el Patrono pueda dedicar sus esfuerzos de manera adecuada a la gestión ordinaria, lo que inevitablemente traerá como consecuencia que el día a día de una Fundación deba ser atendido por terceras personas. Se produce así el fenómeno, bien conocido en otros campos, de la manager's revolution, en cuya virtud, "las fundaciones están principalmente en manos del ejecutivo o de los empleados (por lo que) el gran campo de batalla de las fundaciones y de sus gestores es cómo lograr una mayor implicación de sus pa- 
tronos, quienes deben ser conscientes de que no forman parte de una asamblea o junta general sino de un consejo de administración" (Peñalosa, 2014: 2019).

Recordemos que del correcto funcionamiento del Patronato no depende la mejor obtención de un lucro partible sino la posibilidad de atender adecuadamente necesidades de interés general. Este punto es especialmente importante en la medida de que la actuación de las Fundaciones no se limita a la beneficencia particular, sino que existe hoy una cada vez mayor tendencia a lograr la satisfacción de los intereses generales mediante diferentes tipos de colaboración público-privada que implica la "confluencia de los objetivos, recursos e instrumentos de actuación de las diversas administraciones públicas con distintos tipos de organizaciones privadas en beneficio mutuo" (Antuñano et alt., 2012: 107).

Y en este punto nos encontramos con la paradoja de constatar que, de un lado, los Patronos ponen a disposición de la organización "su tiempo, competencias y experiencia, lo que les acerca a la figura del voluntario, ... son gestores de intereses ajenos y algo más, dado que la fundación se debe al interés general determinado por el fundador ... se convierten en gobernantes de ese interés general" (Peñalosa, 2014: 218); de otro lado, se constata también que la obtención del interés general se ve lastrada por "las ineficiencias de un sector público lento y condicionado por planteamientos políticos, y las ineficiencias del sector lucrativo escorado por la consecución de beneficios (que) habían dejado desatendidos campos de actividad que tenían que ver, directamente, con la mejora de la calidad de vida, los derechos de las personas y/o el bienestar de la sociedad" (Martínez Sánchez, 2013: 70).

Nótese que en el moderno estado del bienestar se ha producido una identificación "más o menos explícita entre lo público y lo estatal, de modo que toda demanda social de cualquier género -cultural, educativa, laboral o sanitaria- se tornaba sin discusión en competencia estatal: todo interés público o general era interés general" (Gomá Lanzón, 2014: 78). Pero, al mismo tiempo, esta identificación tropieza frontalmente con la reducción de la intervención estatal, propia de los reaganomics, en los distintos sectores sociales, también en el Tercer Sector, la cual determinó la "transformación estructural del sector en dirección a la mercantilización de su actividad" (Chaves y Zimmer, 2017: 11).

Y este es, a nuestro juicio, el elemento esencial de la cuestión que obliga a reenfocar el problema de la gratuidad del Patrono: la indisimulada desconfianza experimentada por los poderes públicos hacia la sociedad civil; y al mismo tiempo, su decidida voluntad de erigirse en un moderno Leviatán monopolizador de la necesaria actuación institucional en pos de las personas y actividades merecedoras de especial protección. Baste recordar que durante la tramitación parlamentaria de la Constitución de 1978, el grupo parlamentario entonces mayoritario de la oposición pretendió la supresión de la mención constitucional a la Fundaciones por entender, en palabras del diputado señor Barón Crespo, "injustificable que la función social de la propiedad sea siempre aquella que determine el fundador".

El recelo con que se producen los poderes públicos en sede de Fundaciones es perfectamente comparable con la situación por la que atraviesan las Asociaciones declaradas de utilidad pública, actores también integrantes del Tercer Sector, en las que a pesar del carácter reglado y no discrecional de tal calificación (STS, de 7 de octubre de 2015), la AEAT, de manera comple- 
tamente arbitraria, revoca esta calificación de utilidad pública a las asociaciones que ejercen alguna tipo de actividad económica que les permita recabar fondos destinados al cumplimiento de sus fines. Como hemos tenido ocasión de estudiar en otros trabajos (Palacios, 2019: 102), las pretensiones de la administración serán sistemáticamente rechazadas por el Tribunal Supremo pero, y esto es verdaderamente llamativo, obligará a las Asociaciones a agotar las distintas instancias judiciales para ver restablecido su derecho. Esta desconfianza institucional hacia el Tercer Sector es la causante de que éste soporte siempre (Chaves y Zimmer, 2017: 122) trabas que indistintamente pueden traducirse en "complejidad, fragmentación, duplicidades, trato desigual de las distintas formas de organización" que coartarán su desarrollo.

Por todo lo anterior, el reconocimiento de la labor desempeñada por las distintas entidades integrantes del Tercer Sector en la satisfacción de los intereses sociales permite la imperativa convicción de que las Fundaciones no son meros frutos de la vanidad humana, como las calificaron los enciclopedistas, sino, en palabras del ponente constitucional señor Óscar Alzaga, "uno de los grandes puentes que se ha de tender para salvaguardar el abismo existente entre los individuos y el Estado". Esta afirmación debe conllevar un planteamiento realista en aras a la obtención de recursos. Y desde este punto de vista debe reenfocarse el problema de la gratuidad de los Patronos y por extensión de los administradores del Tercer Sector.

Así, es necesario optar por el tipo de administrador que la Fundación, y en definitiva la sociedad, desea. Cabe mantener un modelo como el actual, en el que la figura del Patrono desempeña una tarea de control honorífico, lastrada por su falta de profesionalización, en la que su cometido fundamental consiste en "abrir puertas en las redes sociales o aportar su imagen a la causa... y como ... window dressing directors ... se produce una despreocupación de la marcha de la organización y una irreflexiva tendencia a dejar la estrategia y la gestión de la organización en manos de gerentes y empleados, de los que acaban siendo rehenes" (Paz Ares, 2008: 154). 0 bien, por el contrario, cabe reconocer que "un patrono que gestiona y dirija directamente la fundación y se dedica en exclusividad a la misma es un profesional y, como tal debe ser remunerado. Es más, otra solución conduce generalmente a una mala gestión económica" (Blázquez Lidoy, 2005: 89).

Y creemos, reconociendo las dificultades de la tarea, que la solución debe inspirarse en los planteamientos apuntados por la STC 18/1984, de 7 de febrero, a tenor de la cual "una de las características del estado social y de derecho es que los intereses generales se definen a través de una interacción entre el Estado y los agentes sociales, y que esta interacción entre lo público y lo privado trasciende también al campo de lo organizativo, en donde como es fácil de entender, las fundaciones desempeñan un papel de primera magnitud". Para ello, en primer lugar, insistimos, se necesita superar la desconfiada visión estatista que limita la realización de actividades industriales o mercantiles por parte de Fundaciones a las "estrictamente necesarias para el mejor cumplimiento del fin fundacional (antiguo Reglamento de Fundaciones Culturales Privadas -Decreto 2930/1972, de 21 de julio-) o "cuyo objeto esté relacionado con los fines fundacionales o sean complementarias o accesorias de las mismas" (art. 24.1 Ley 50/2002). Esto es admitir sin prejuicios la realización de actividades económicas por parte 
de las Fundaciones, estableciendo además los necesarios controles y reubicando al Patrono en una más adecuada posición de verdadero gestor de operadores económicos en el mercado.

De esta manera la configuración gratuita del cargo de Patrono debe ser incardinarse en un replanteamiento global del régimen fiscal de las entidades no lucrativas y del mecenazgo que aborde íntegramente su acomodación a un entorno cambiante. No podemos limitarnos, como hizo la inconclusa reforma de 2015, al micromecenazgo y al incremento de tipos, sin afrontar los "problemas basilares del mecenazgo" (Blázquez Lidoy, 2015: 197). Creemos por el contrario que nos encontramos, como ya apuntara Alli Turillas (2012: 213) ante una "transición hasta un momento que aparenta ser de no retorno (que precisa) de mejor y mayor regulación". Y este momento de transición debe descansar en tres elementos fundamentales:

En primer lugar, es necesario que los poderes públicos admitan el postulado fundamental de la materia: las Fundaciones ostentan una legitimidad propia que debe ser respetada por el Estado. Esta legitimidad tiene su traducción igualmente en el aspecto organizativo en el que la figura del Patrono ostenta una posición preeminente, singular y distinta de la propia de otros actores con los que puede compartir competencias. Por ello estimamos especialmente desafortunada la solución que para las fundaciones catalanas impuso la Ley 4/2008 de 24 de abril. En virtud de esta norma, las Fundaciones en las que concurrían dos o más de determinadas circunstancias (contar con más de veinticinco trabajadores, activo superior a seis millones, importe anual de ingresos superior a tres millones de euros) quedaban obligadas a separar las funciones de Patrono y gestor, contratando para ello a una o más personas, necesariamente no patronos, para que ejercieran la dirección de la gestión ordinaria de la fundación y ejercicio de los acuerdos ordinarios del Patronato. La Exposición de Motivos del CC de Cataluña afirmó que esta opción había sido acogida por el sector fundacional como "medidas de buena práctica" que "refuerzan el principio no lucrativo, fomentan la profesionalización de la gestión y reafirman la posición soberana e independiente que debe tener el órgano de gobierno en su función de control de las decisiones ejecutivas tomadas por el equipo de gestión". Tras solamente cuatro años de vigencia, el propio legislador catalán tuvo que derogar esta obligatoriedad (art. 9 Ley 7/2012, de 15 de junio), estableciendo un sistema facultativo en línea con el existente en Castilla y León (art. 14.3 Ley 13/2002) y La Rioja (art. 17.3 Ley 1/2007).

Descartado que el legislador catalán quisiera arbitrar soluciones meramente provisionales o a título de tanteo, solamente cabe concluir que estamos ante el afán intervencionista de la administración quien, pese a reconocer el principio de autoorganización (art. 312 CCC), quiere arrogarse la posibilidad de obligar a las Fundaciones a contratar, o a no contratar, a determinados cargos sin plantear las necesidades individuales de cada una de ellas; exige la presentación de un plan de viabilidad de económica para los dos primeros años de vida de la fundación (331-7 CCC), sin parangón en el mundo societario; y se reserva por último la posibilidad de nombrar directamente a los Patronos en determinadas circunstancias (art. 332-6 CCC). En definitiva, y por partes iguales, anticuado intervencionismo administrativo y desconfianza hacia el Tercer Sector que, como ha tenido que reconocer el preámbulo de la propia ley catalana de reforma 7/2012 "ha supuesto a veces un freno en la creación de nuevas fundaciones". 
La segunda premisa que debe marcar la evolución de la materia consiste en la afirmación de que los poderes públicos deben coadyuvar a la consecución del interés general mediante el establecimiento de un régimen fiscal que incentive el funcionamiento de las Fundaciones y por ende del Tercer Sector. Veamos un ejemplo -extremo- de lo que no debe hacerse. El art. 5 bis del Dto. Legislativo 1/2014, de 6 de junio, por el que se aprueba el TR de las disposiciones legales de la C.A. de las Illes Balears en materia de tributos cedidos por el Estado, establece una deducción del 15\% por "donaciones, cesiones de uso o contratos de comodato y convenios de colaboración empresarial, relativos al mecenazgo cultural, científico y de desarrollo tecnológico y al consumo cultural", pero condicionando esta deducción a que la base imponible del donante en sede del IRPF no exceda de 12.500 euros anuales o de 25.000 si tributa en forma conjunta. Creemos que la norma, y las intenciones del legislador al establecer un límite a la deducción como el apuntado, son suficientemente elocuentes como para precisar comentario alguno.

En tercer y último lugar, la propia figura del Patrono debe ser reenfocada. Si admitimos que las Fundaciones satisfacen intereses sociales cuando menos con la misma legitimidad con la que puede hacerlo el Estado, debemos admitir también que al frente de estas entidades debe encontrarse una persona plenamente capaz para cumplir su función. Y para ello debemos reconocer que un Patrono gratuito no puede dedicarse con habitualidad a realizar tareas de gestión; y al mismo tiempo hay que admitir también que entre Patronos y gestores existen divergencias e incluso conflictos de intereses semejantes a los habituales en el mundo societario entre propietarios y gestores. La adecuada conjunción de ambas circunstancias debe llevarnos a buscar algunas alternativas.

Parte de la solución se encuentra en el reconocimiento de que bajo la única denominación de "Patrono" se engloban realidades muy distintas: existe un primer tipo de Patrono puramente honorífico, que presta su nombre a una causa altruista y se desvincula completamente del día a día de la Fundación; y existe también un Patrono encargado de la gestión ordinaria de la misma, haya entablado o no la Fundación relaciones con terceras personas ajenas en este sentido. Seguramente ambas categorías sean igualmente necesarias en aras de la consecución del fin general propio de la Fundación, pero su régimen no puede ser el mismo.

Respecto del Patrono que pudiéramos denominar "honorífico", aquel que presta su nombre para facilitar las relaciones de la fundación, parece razonable mantener la actual gratuidad del cargo: nos encontramos ante una actividad filantrópica y como tal debe ser tratada. En cambio, su régimen de responsabilidad, por más que pueda ser moderado judicialmente, parece más concebido para dificultar la colaboración de personas socialmente reconocidas en actividades altruistas que para disciplinar la responsabilidad derivada de una actuación en la que esta persona no ha intervenido de manera efectiva.

Cuestión distinta debe ser el régimen del Patrono "gestor", esto es aquel que, con independencia de que la Fundación pueda encargar tareas determinadas a un tercero, se ve involucrado en el día a día. Respecto de este Patrono, las reticencias históricas que pesan sobre las fundaciones como operadores económicos en el mercado ceden ante la constatación de que el interés general puede ser alcanzado también mediante actuaciones privadas. Y esta actuación 
privada requiere de fuentes de financiación estables, no limitadas expresamente a lo marcado por la dotación fundacional; dicho de otro modo, requiere el reconocimiento de la posibilidad de que la fundación actúe como operador económico, y por tanto el reconocimiento de la evolución de la realidad fundacional en la que "la influencia del derecho societario ha sido y es cada día más notable" (Peñalosa, 2016: 190) y de ahí "la necesidad de contar con figuras e instituciones que sólo el derecho de sociedades ha estado en condiciones de proporcionar" (Embid Irujo: 2009, 137). La conclusión inevitable, aunque todavía no mayoritaria (Véase, en contra, Ruiz Jiménez, 2009: 952) es el acercamiento en orden a la responsabilidad de este segundo tipo de Patronos a la disciplina mercantil y también la necesaria retribución de los servicios por él prestados.

\section{Conclusiones}

Primera.- El Tercer sector, y dentro él las Fundaciones, permite atender necesidades reales de personas y actividades merecedoras de especial protección. Tanto es así que una característica "del estado social y de derecho es que los intereses generales se definen a través de una interacción entre el estado y los agentes sociales (donde) las fundaciones desempeñan un papel de primera magnitud" (STC 18/1984, de 7 de febrero).

Segunda.- En nuestro sistema, la gratuidad del cargo de Patrono tiene carácter absoluto. Su retribución implica la imposibilidad de que la Fundación pueda optar por el régimen fiscal privilegiado establecido por la Ley 49/2002. El fundamento de esta exigencia se encuentra en el intento de evitar que mediante la retribución de los Patronos se produzca una forma indirecta de vinculación de bienes. Sin embargo, la gratuidad del cargo no forma parte del denominado contenido esencial del derecho a crear Fundaciones; es decir, se trata simplemente de una opción legislativa tan válida como la contraria.

Tercera.- La gratuidad del cargo queda igualmente modalizada al delimitar la norma su derecho al reembolso de los gastos, debidamente justificados, ocasionados por el desempeño de su función, con los límites establecidos en sede del IRPF para ser considerados dietas exceptuadas de gravamen (art. 9 RIRPF). Sin embargo, es difícil entender estas limitaciones al derecho de reembolso que vincula las cantidades a reembolsar a los Patronos a unos límites establecidos en otra norma (LIRPF), para otros destinatarios (trabajadores por cuenta ajena) y para otros fines (dietas exceptuadas de gravamen).

Cuarta.- El legislador no articula un sistema de control a posteriori por parte del Protectorado, que debiera ser adaptable a la multiplicidad de situaciones posibles, sino que, conscientemente, limita la indemnidad de un Patrono que asume una serie de gastos presumiblemente beneficiosos para la Fundación. Por ello no cabe sino colegir que el legislador, limitando las posibilidades de actuación de los Patronos, entorpece la actividad de las fundaciones, tomando para sí el control de actividades altruistas propias de la sociedad civil. Esta gratuidad del cargo de Patrono es igualmente de aplicación a los administradores que representen a la Fundación 
en las sociedades mercantiles en que participe, salvo que las retribuciones percibidas por su condición de administrador se reintegren a la entidad que representen.

Quinta.- Si el objetivo de la norma es la protección de entidades que, como las Fundaciones, coadyuvan a la consecución de fines de interés general, no cabe establecer rémora alguna -mediante una prohibición general del carácter retribuible de su órgano de administración- a la eficiencia de estas entidades integrantes del Tercer Sector. Por el contrario la norma debiera centrar sus esfuerzos en velar por el efectivo destino de las rentas e ingresos de las fundaciones (así como el de su patrimonio en caso de su disolución) a los objetivos constitutivos de la entidad, imposibilitándose cualquier desviación respecto a los fines de interés general perseguidos. Esta es la cuestión nuclear del régimen y a la que deben supeditarse, de forma ponderada, el resto de requisitos establecidos en el art. 3 de la Ley 49/2002.

Sexta.- Si comparamos la taxativa gratuidad del cargo de Patrono con el resto de los requisitos exigidos por la Ley 49/2002 para la aplicación del régimen fiscal privilegiado vemos que su traducción práctica es diferente. Si la gratuidad se configura con carácter absoluto, los restantes requisitos del art. 3 de la LRF-ENL (con la sola excepción atinente al destino de sus bienes caso de disolución) resultan suavizados doctrinal, jurisprudencial o legalmente.

Séptima.- Este rigor en la apreciación de la gratuidad del cargo, fruto de la desconfianza del Estado frente a la sociedad civil, se plasma en las deficiencias de que adolece su regulación, en donde al tiempo que se somete al Patrono a una responsabilidad más propia de la pura actividad mercantil ve coartada sus posibilidades de actuación.

Octava.- La denominación "Patrono" engloba dos realidades muy diferentes: de un lado el Patrono puramente honorífico, desvinculado completamente del día a día de la Fundación, al que no se debería someter a un régimen de responsabilidad como el existente y, de otro, el Patrono que puede dedicar sus esfuerzos a la gestión ordinaria de la misma.

Novena.- Respecto de este Patrono "gestor", la necesidad de que las Fundaciones dispongan de medios de financiación estables, alejados en el tiempo de la dotación inicial, nos lleva a abogar por una progresiva agilización de su actuación en el mercado, acercando la responsabilidad del Patrono a la disciplina mercantil y permitiendo paralelamente la retribución de los servicios por él prestados.

Décima.- La configuración de la gratuidad del cargo de Patrono debe ser incardinada en un replanteamiento global del régimen fiscal de las entidades no lucrativas y del mecenazgo que aborde su acomodación normativa a un entorno permanentemente cambiante.

Decimoprimera.- Para concluir, entendemos que la verdadera reforma que espera el mecenazgo es un cambio de actitud de los poderes públicos que, eliminando desconfianzas y paternalismos, establezca una colaboración abierta con la sociedad civil, en especial con las Fundaciones que son, en palabras de Óscar Alzaga "uno de los grandes puentes que se ha de tender para salvaguardar el abismo existente entre los individuos y el Estado". 


\section{Bibliografía}

ALLI TURILLAS, J.C. (2012): "Origen, crisis jurídica y cambios en ciernes en la regulación del sector no lucrativo de tipo fundacional en los EE.UU.", Revista Española del Tercer Sector, 21, 197-227.

ANTUÑANO MARURI, I. \& BARCO, S. \& BOTELLA, C. \& DE DIOS GARCÍA, J. (2012): “Análisis de la colaboración público-privada en los procesos de colaboración al desarrollo que implican a la economía social". En: La economía social y la cooperación al desarrollo. Una perspectiva internacional, Universitat de Valéncia, Fundació General, Patronat Sud-Nord, Valencia.

BLÁZQUEZ LIDOY, A. (2005): "Relaciones sobre el IVA y la Ley 49/2002 del Régimen Fiscal de las Entidades sin Ánimo de Lucro", Revista Centro de Estudios Financieros, 262, 77-101.

BLÁZQUEZ LIDOY, A. \& MARTÍN DÉGANO, I. (2012): Manual tributario de entidades no lucrativas (asociaciones y fundaciones), Centro de Estudios Financieros, Madrid.

BLÁZQUEZ LIDOY, A. (2015): “La no revisión de la ley del mecenazgo: historia de una reforma inconclusa”. Ius canonicum, 55, 197-229.

CAFFARENA LAPORTA, J. (2009): "Las fundaciones: fines de interés general, beneficiarios y cláusulas de reversión". En: Anuario de Derecho de Fundaciones, 29-58. Iustel Portal del Derecho, SA., Madrid.

CALVO ORTEGA, R. (2016): “Tercer Sector y Estado Social”. En: Nuevo Tratado de Fundaciones. Aranzadi Thomson Reuters, Cizur Menor (Navarra).

CHAVES ÁVILA, R. \& ZIMMER, A. (2017): El tercer sector España y en Europa Crisis y resiliencia, Fundación General Universidad de Valencia, La Nau Solidaria, Valencia.

CHAVES ÁVILA, R. \& MONZÓN CAMPOS, J.L. (2018): “La economía social ante los paradigmas económicos emergentes: innovación social, economía colaborativa, economía circular, responsabilidad social empresarial, economía del bien común, empresa social y economía solidaria". CIRIEC-España, Revista de Economía Pública, Social y Cooperativa, 93, 5-50.

DOI: 10.7203/CIRIEC-E.93.12901.

DE LORENZO GARCÍA, R. \& PIÑAR MAÑAS, J.L. \& SANJURJO GONZÁLEZ, T. (2011): “Reflexiones e torno a las fundaciones y propuestas de futuro". En: Anuario de derecho de fundaciones, Iustel.

DÍAZ-AGUADO JALÓN, C. (2018): "Las Fundaciones", CIRIEC-España, Revista Jurídica de Economía Social y Cooperativa, 32, 269-304.

EMBID IRUJO, J.M. (2009): “Obligaciones y Responsabilidad de los Patronos". En: Anuario de Fundaciones, 131-151. Iustel, Madrid. 
EMBID IRUJO, J.M. (2019): "Actividad económica en el mercado e interés general. Sobre el derecho de fundaciones de nuestro tiempo", Boletín Oficial del Estado. Colección: Derecho Privado no 18 . ISBN: 9788434026032.

ESEVERRI MARTÍNEZ, E. (2008): Régimen fiscal de las entidades sin fines lucrativos: requisitos. En: Estudios en Homenaje al Profesor Pérez de Ayala, 687-723, Dykinson, Madrid.

GARCÍA-ANDRADE GÓMEZ, J. \& PINDADO GARCÍA, F. (2016): “Concepto y ámbito subjetivo de aplicación”. En: De Lorenzo García, R. \& Piñar Mañas, J.L. \& Sanjurjo González, T. (Dirs.) Nuevo Tratado de Fundaciones, Aranzadi Thomson Reuters, Navarra.

GOMÁ LANZÓN, J. (2014): “Carta a las fundaciones españolas”. Real Maestranza de Caballería de Ronda. Pre-Textos. Valencia.

LÓPEZ DÍAZ, A. (2001): "Régimen fiscal de las fundaciones". En: Yebra Martul-Ortega, P., Fundaciones y Mecenazgo. Régimen fiscal, Comares, Sevilla, 21-82.

LÓPEZ-NIETO Y MAYO, F. (2006): La ordenación legal de las fundaciones, Editorial La Ley, Madrid.

MARIMÓN DURÁ, R. \& OLAVARRÍA IGLESIA, J. (2008): “Gobierno de la Fundación”. En: Comentarios a la Ley de Fundaciones, Tirant lo Blanch, Valencia.

MÁRQUEZ SILLERO, C. (2007): “Gratuidad de los cargos de patrono, representante y administradores de la fundación en sociedades mercantiles participadas". En: La exención de las fundaciones en el Impuesto de sociedades conforme a la Ley 49/2002, La Ley 82/2010.

MARTÍN DÉGANO, I. (2015): "Las fundaciones y el cumplimiento indirecto de los fines de interés general. En torno a la interpretación restrictiva de las exenciones", Revista Contabilidad y Tributación, 487, 139-144.

MARTÍN PASCUAL, C. (2003): El régimen fiscal de las entidades sin fines lucrativos en la Ley 49/2002, de 23 de diciembre, Ministerio de Hacienda, Instituto de Estudios Fiscales, Colección: Estudios Jurídicos.

MARTÍNEZ SÁNCHEZ, J.L. (2013): “La profesionalización de la dirección en las instituciones no lucrativas españolas: nuevos retos, nuevos perfiles", Participación Cívica y Filantropía, 872, 69-77.

MECO TÉBAR, F. (2008): "Artículo 26. Obtención de ingresos"; "Artículo 27. Destino de rentas e ingresos". En: Comentarios a la Ley de Fundaciones, Tirant lo Blanch, Valencia.

MONZÓN CAMPOS, J.L. \& CHAVES ÁVILA, R. (Dirs.) (2012): La Economía Social en la Unión Europea, Comité Económico y Social Europeo (CESE), Bruselas. 
OREJAS CASAS, J.A. (2018): "La organización y dirección de las fundaciones", CIRIEC-España, Revista jurídica de Economía Social y Cooperativa, 32, 305-371.

OREJAS CASAS, J.A. (2019): Fundaciones: fines, gestión y buen gobierno, Tesis Doctoral. http:// uvadoc.uva.es/handle/10324/37855. D0I: 10.35376/10324/37855.

PALACIOS RONDA, E. (2018): "Financiación de Asociaciones: especial examen del ejercicio de actividades económicas", GIZAEKOA, Gizarte Ekonomiaren Euskal Aldizkaria, Revista Vasca de Economía Social, 15, 154-179.

PALACIOS RONDA, E. (2019): “Utilidad Pública de las Asociaciones. Revocación por la Administración y Solución Fundacional", REVESCO. Revista de Estudios Cooperativos. Ediciones Complutense, Madrid, 130, 99-121. DOI.ORG/10.5209/REVE.60987.

PAZ ARES, C. (2008): "El buen gobierno de las organizaciones no lucrativas". En: La Filantropía: tendencias y perspectivas, homenaje a Rodrigo Uría Meruéndano, Fundación de estudios financieros. Madrid, 147-158.

PEDREIRA MENÉNDEZ, J. (2003): El régimen fiscal del sector no lucrativo y del mecenazgo. Comentarios a la Ley 49/2002, de 23 de diciembre, de régimen fiscal de las entidades sin fines lucrativos y de los incentivos fiscales al mecenazgo, Thomson Civitas, Madrid.

PEÑALOSA ESTEBAN, I. (2014): "Buen Gobierno Fundacional". En: Sociedad civil, inclusión social y sector Fundacional en España. Estudios en homenaje a Carlos Álvarez Jiménez, CERMI Comité español de Representantes de Personas con Discapacidad, Madrid, 215-230.

PEÑALOSA ESTEBAN, I. (2016): “Órganos de gobierno y relación con los poderes públicos”. En: Nuevo Tratado de Fundaciones, Aranzadi Thomson Reuters, Cizur Menor (Navarra).

PÉREZ ESCOLAR, M. (2008): La actividad económica de las fundaciones. Tensiones legislativas e interés general, Thomson Civitas, Cizur Menor (Navarra).

PIÑAR MAÑAS, J.L. (1996): "El derecho de fundación como derecho constitucional", Revista Derecho Privado y Constitución, 9, 147-183.

RODRIGO RUIZ, M.A. (2017): “Consideraciones en torno al establecimiento de un régimen tributario común para las entidades de la economía social", REVESCO, Revista de Estudios Cooperativos, 125, 187-212. DOI: 10.5209/REVE.57064.

RUIZ JIMÉNEZ, J. (2009): "No es posible equiparar la responsabilidad de los patronos de las fundaciones con los administradores de las sociedades mercantiles", Revista crítica de derecho inmobiliario, ISSN 0210-0444, 712, 952-958.

SERRANO CHAMORRO, MaE. (2019): El ejercicio del cargo de patrono en las Fundaciones, Thomson Reuters Aranzadi, Cizur Menor (Navarra). 